\title{
Consumers and Artificial Intelligence: An Experiential Perspective
}

\author{
STEFANO PUNTONI \\ REBECCA WALKER RECZEK \\ MARKUS GIESLER \\ SIMONA BOTTI*
}

*Stefano Puntoni is Professor of Marketing (spuntoni@rsm.nl) at the Rotterdam School of Management, Erasmus University, Burgemeester Oudlaan 50, Rotterdam, 3062 PA, the Netherlands. Rebecca Walker Reczek is Dr. H. Lee "Buck" Mathews Professor of Marketing (reczek.3@osu.edu) at the Fisher College of Business, The Ohio State University, 2100 Neil Avenue, 506A Fisher Hall, Columbus, OH 43210. Markus Giesler is Associate Professor of Marketing (mgiesler@ schulich.yorku.ca) at the Schulich School of Business, York University, 4700 Keele Street, Toronto ON M3J1P3. Simona Botti is Professor of Marketing (sbotti@london.edu) at London Business School, Regent's Park, London NW14SA, United Kingdom. The authors thank Carl Mela and the Marketing Science Institute for organizing the 2018 MSI Scholars conference that provided the opportunity to work together on this project, Christine Moorman and John Deighton for their guidance, participants at the Marketing Science conference in Rome for their feedback, and Gizem Yalcin for her help and feedback. Order of authorship was determined by random draw; all authors contributed equally. 


\title{
Consumers and Artificial Intelligence: An Experiential Perspective
}

\begin{abstract}
Artificial intelligence (AI) helps companies offer important benefits to consumers, such as health monitoring with wearable devices, advice with recommender systems, peace of mind with smart household products, and convenience with voice-activated virtual assistants. However, while AI can be seen as a neutral tool to be evaluated on efficiency and accuracy, this approach does not consider the social and individual challenges that can occur when AI is deployed. This research aims to bridge these two perspectives: on one side, we acknowledge the value that embedding AI technology into products and services can provide to consumers; on the other side, we build on and integrate sociological and psychological scholarship to examine some of the costs consumers experience in their interactions with AI. In doing so, we identify four types of consumer experiences with AI: (1) data-capture, (2) classification, (3) delegation, and (4) social. This approach allows us to discuss policy and managerial avenues to address the ways in which consumers may fail to experience value in organizations' investments into AI and to lay out an agenda for future research.
\end{abstract}

Keywords: artificial intelligence, AI, customer experience, technology marketing, Internet of Things, privacy, discrimination, replacement, alienation 
Not long ago, Artificial Intelligence (AI) was the stuff of science fiction. Now it is changing how consumers eat, sleep, work, play, and even date. Consider the diversity of interactions consumers might have with AI throughout the day, from Fitbit's fitness tracker and Alibaba's Tmall Genie smart speaker to Google Photo's editing suggestions and Spotify's music playlists. Given the growing ubiquity of AI in consumers' lives, marketers operate in organizations with a culture increasingly shaped by computer science. Software developers' objective of creating technical excellence, however, may not naturally align with marketers' objective of creating valued consumer experiences. For example, computer scientists often characterize algorithms as neutral tools evaluated on efficiency and accuracy (Green and Viljoen 2020), an approach that may overlook the social and individual complexities of the contexts in which AI is increasingly deployed. Thus, whereas AI can improve consumers' lives in very concrete and relevant ways, a failure to incorporate behavioral insight into technological developments may undermine consumers' experiences with AI.

This paper aims to bridge these two perspectives: on one side, we acknowledge the benefits that AI can provide to consumers; on the other side, we build on and integrate sociological and psychological scholarship to examine the costs consumers can experience in their interactions with AI. Exposing the tension between these benefits and costs, we offer recommendations to guide managers and scholars investigating these challenges. In so doing, we respond to the call from the Marketing Science Institute to examine "the role of the human/tech interface in marketing strategy" and to offer more scholarly attention to situations where "customers face an array of new devices with which to interact with firms, fundamentally altering the purchase experience" (Marketing Science Institute 2018). 
We begin by offering a framework that conceptualizes AI as an ecosystem with four capabilities. We focus on the consumer experience of these capabilities, including the tensions felt. We then offer more insights into the experience of these tensions at a macro level, by exposing relevant and often explosive narratives in the sociological context, and at the micro level, by illustrating them with real-life examples grounded in relevant psychological literature. Using these insights, we provide marketers with recommendations regarding how to learn about and manage the tensions. Paralleling the joint emphasis on social and individual responses, we make recommendations outlining both the organizational learning in which firms should engage to lead the deployment of consumer AI and the concrete steps they should take to design improved consumer AI experiences. We close with a research agenda that cuts across the four consumer experiences and suggests ideas for how researchers might contribute new knowledge on this important topic.

\section{Understanding the Consumer AI Experience}

We conceptualize AI as an ecosystem comprising three fundamental elements- data collection and storage, statistical and computational techniques, and output systems - that enable products and services to perform tasks on behalf of humans typically understood as requiring intelligence and autonomous decision making (Agrawal, Gans, and Goldfarb 2018). These elements are associated with capabilities. Data collection devices listen, in the broad sense of gathering information from different sources; for example, product sensors scan the environment and wearable devices record physical activity. Algorithms leverage this information to predict; for example, Spotify serves music suggestions via personalized playlists. Finally, output systems produce a response or communicate with consumers, for example by directing a vehicle or responding through consumer interfaces like Baidu's Duer. 
To articulate a customer-centric view of AI, we move attention away from the technology toward how the AI capabilities are experienced by consumers. Consumer experience relates to the interactions between the consumer and the company during the customer journey and encompasses multiple dimensions: emotional, cognitive, behavioral, sensorial, and social (Brakus, Schmitt, and Zarantonello 2009; Lemon and Verhoef 2016). Our framework is built on four experiences that reflect how consumers interact with the four AI capabilities (Figure 1). This experiential perspective helps shed light on the affective and symbolic aspects of technology consumption in addition to the utilitarian and functional ones (Mick and Fournier 1998). Data-capture is the experience of endowing individual data to AI; classification is the experience of receiving AI's personalized predictions; delegation is the experience of engaging in production processes where the AI performs some tasks on behalf of the consumer; social is the experience of interactive communication with an AI partner.

--- Figure 1 about here ---

For each experience we identify benefits and costs from a consumer perspective and propose that managers qualify their focus on the former by paying attention to the latter. A datacapture experience may serve or exploit consumers; a classification experience may understand or misunderstand them; a delegation experience may empower or replace consumers; a social experience may connect or alienate them. Each of these experiences, their social science connections, managerial implications, and future research directions are now examined.

\section{The AI Data-Capture Experience}

The listening capability enables AI systems to collect data about consumers and the environment in which they live. We conceptualize the resulting experience as data-capture, which includes different ways in which data are transferred to the AI. Data can be intentionally 
provided by consumers, although with different degrees of understanding of the process: data are shared when there is little or no uncertainty about how they will be used and by whom, or they are surrendered when this uncertainty is high (Walker 2016). Data can also be obtained by AI from the "shadows" consumers leave behind when they engage in daily activities, as in the case of a shopper perusing a store equipped with facial recognition technology or of an iRobot Roomba creating a map of a residential space (Kuniavsky 2010).

The data-capture experience provides benefits to consumers because it can make them feel as if they are served by the AI: the provision of personal data allows consumers access to customized services, information, and entertainment, often for free. For example, consumers who install the Google Photos app let Google capture their memories but in return get an AI-powered assistant that suggests context-sensitive actions when viewing photos. Access to customized services also implies that consumers can enjoy the outcome of decisions made by digital assistants, which effectively match personal preferences with available options, without having to endure the cognitive and affective fatigue that decision-making can entail (André et al. 2018). Finally, access to customized services offer unprecedented opportunities for self-improvement; consider one of the projects within Alphabet, where data from smartphones, genomes, wearables, and ambient sensors are combined to drive personalized healthcare (https://on.ft.com/3euohbB).

Despite AI's ability to predict and satisfy preferences, consumers can feel exploited in data-capture experiences, mainly because they do not understand AI's operating criteria. This can be attributed to several features of AI. First, the modalities of data acquisition are becoming increasingly intrusive and difficult to avoid. Second, even when consumers intentionally share information, they are not aware of how this information is aggregated over time and across contexts. Finally, data brokers are largely unregulated and often lack transparency and 
accountability (Grafanaki 2017). As a result, data-capture experiences may threaten consumers' ownership of personal data and challenge personal control, that is, the feeling that events are determined by the self, rather than by others or by external forces and can be stirred towards desired outcomes (DeCharms 1968). The consequences of this loss of control are examined next from both a sociological and psychological perspective.

\section{Sociological Context: The Surveillance Society Narrative}

In popular culture, lack of ownership over personal data has been frequently associated with a loss of personal control stemming from technology's threatening potential to enable monitoring of human behavior. Stories such as George Orwell's 1984 or Philip K. Dick's Minority Report envision systems of oppression where, due to lack of privacy and constant surveillance, people can no longer control their destiny. This dystopian imagination is echoed in sociological scholarship that associates data capture with the rise of a capitalist marketplace where private information becomes the central form of capital (Zuboff 2019).

Such dystopian concerns strike a resonant chord when considering Google's move in the early-2000s to transform consumer data from a by-product into an economic asset that formed the basis of a new type of commerce driven by the ability to colonize the consumer's private experience. This commerce contributes to a surveillance marketplace, in which data surplus is "fed into advanced manufacturing processes known as 'machine intelligence,' and fabricated into prediction products that anticipate what you will do now, soon, and later" (Zuboff 2019, 14). To illustrate the power of this commerce, targeted ads based on personality characteristics inferred from the analysis of Facebook likes in combination with online survey questions can increase conversion rates by about 50\% (Matz et al. 2017); in 2018, Facebook's revenues from the sales of such tailored ads was close to $\$ 56$ billion (https://on.ft.com/2UZ8Ykv). 
From the perspective of this narrative, technology companies are not only required to find ever new ways to make monitoring and surveillance palatable to consumers by linking it to convenience, productivity, safety, or health and wellbeing (Bettany and Kerrane 2016); they must also constantly push the boundaries of what private information should be shared (Giesler and Humphreys 2007) through a complex landscape of notifications, reminders, and nudges intended to initiate behavioral change. Thus, as consumer behavior becomes increasingly retailored to the exigencies of behavioral futures, AI can transform consumers into subjects who are complicit in the commercial exploitation of their own private experience, thereby undermining personal control and promoting the concentration of knowledge and power in the hands of those who own their information.

\section{Psychological Perspective: The Exploited Consumer}

Data-capture experiences are characterized by an underlying tension: consumers recognize that data-capture allows AI to serve them through customization, but its inherent lack of transparency makes them feel exploited. These feelings of exploitation are fuelled by actual and perceived loss of personal control, with important psychological consequences (Botti and Iyengar 2006). The first of such consequences is negative affect, which can turn into demotivation and helplessness. Consider the case of Leila, a sex worker who shielded her identity on her Facebook account and reported being shocked to see some of her regular clients recommended by the "People You May Know" function. According to Leila: "the worst nightmare of sex workers is to have your real name out there, and Facebook connecting people like this is the harbinger of that nightmare." For Leila, like for domestic violence victims or political activists, privacy invasion is not only frightening, it may become a matter of life, death, or time in jail (https://bit.ly/2CtU0g5). 
As being in control is a basic need and a pre-condition of psychological welfare (Leotti, Iyengar, and Ochsner 2010), the second consequence of loss of personal control may be moral outrage. Consider the case of a German consumer who requested his own data from Amazon and received transcripts of Alexa's interpretations of voice commands, even though he did not own any Alexa devices. The consumer relayed his story to a local magazine, which attempted to identify the consumer whose privacy had been compromised. The magazine staff involved in this experience described it as follows: “[we were able to] navigate around a complete stranger's private life without his knowledge, and the immoral, almost voyeuristic nature of what we were doing got our hair standing on end" (https://bit.ly/3ek2rsg).

The third consequence of loss of personal control relevant in data-capture experiences is psychological reactance, a motivational state directed to restore control after a restriction (Brehm 1966), which causes more negative evaluations of and hostile behaviors toward the source of the restriction; in marketing, reactance can decrease the likelihood to repurchase and follow recommendations (Fitzsimons and Lehmann 2004). Illustrating reactance in AI data-capture experience is Danielle, a U.S. consumer who installed Echo devices throughout her home, believing Amazon's claims that they would not invade her privacy. When one of her Alexas recorded a private conversation and sent it to a random number in her address book, Danielle said "I felt invaded," and concluded: "I'm never plugging that device in again, because I can't trust it" (https://bit.ly/3ey0Sag).

In sum, consumers may experience data-capture as a form of exploitation: whereas technology companies, firms, and governmental agencies gain financial and political power, consumers lose ownership of their data and feel a loss of control over their lives. As we discuss next, managers should gain a better understanding of feelings of exploitation, as they prevent 
consumers from seeing the value firms can provide through data-capture. This understanding starts at the organizational level and is then translated into decisions about experience design.

\section{Managerial Recommendations: Understanding the Exploited Consumer}

Organizational Learning. A central programmatic task in addressing the issue of consumer exploitation in AI data-capture experiences involves determining and enhancing the organization's level of awareness around the sociological and psychological costs raised in the previous sections. Companies should strive towards greater organizational sensitivity around consumer privacy and the current asymmetry in the level of control over personal data. For instance, they should use netnographic observation or sentiment analysis to listen empathetically and at scale to consumers who have experienced exploitation in AI data-capture experiences. Further, rather than accepting the surveillance society narrative at face value, firms can use these tools to understand when, how, and whether their own data-capture experiences play into versus subvert this narrative. Likewise, companies should draw on insights by privacy scholars and activist movements to question their taken-for-granted beliefs. In doing so, for instance, companies could realize that their own view on privacy default settings might differ markedly from that of a vulnerable consumer group and adjust their processes accordingly (Martin and Murphy 2017).

Organizational learning can also extend beyond the boundaries of the individual firm to encompass other institutions. First, companies could sponsor research aimed at understanding the influence of surveillance-society-style thinking on their culture and practice, as well as its negative impact on marketing activities and consumers. Second, companies could adopt a more communal approach to sharing individual organizational learning with other firms, industry associations, educators, and the media. Third, industry groups could collaborate with scholars to 
create and adopt an algorithm bill of rights for individuals (Hosanagar 2019), which some AI experts have proposed should include a right to transparency, for example, "the right to know when an algorithm is making a decision about us, which factors are being considered by the algorithm, and how those factors are being weighted" (https://bit.ly/39A6EWY).

Experience Design. Based on this organizational learning, organizations should design improved AI data-capture experiences. Recent regulations, such as the European Union's General Data Protection Regulation, aim to limit exploitation by making organizations responsible for giving consumers the possibility to opt into specific data-collection processes (e.g., cookies) and to ask for greater clarity on how these data are used.

As AI becomes more pervasive and ubiquitous, however, ensuring consumer consent at all steps of the customer journey may result in an overload of choice and information that decreases, instead of increases, personal control (Iyengar and Lepper 2000) and exacerbates the negative affective and behavioral reactions illustrated above. Interventions related to the way in which options are presented — the choice architecture - can reduce the cognitive and affective costs associated with excessive information and choice (Chernev, Böckenholt, and Goodman 2015) and therefore give consumers greater control over their data without overloading them. Among such interventions, including default options has proven especially effective in facilitating decision-making, but also in influencing specific behaviors (Thaler and Benartzi 2004). Because individuals tend to passively accept defaults instead of exercising their right to opt out, the selection of defaults by the choice architects may lead to suboptimal outcomes when it does not properly consider preference heterogeneity. The personalization of defaults could mitigate this issue (Sunstein 2015), and AI itself could assist consumers in the automatic implementation of preferences about how their data are captured and analyzed. 
More broadly, organizations can limit consumer exploitation by playing an active role in educating consumers about the costs and benefits entailed in AI data-capture experiences; for example, the recently overhauled Google Home app clearly communicates what user data has been stored and why. Understanding the potential for exploitation in data-capture experiences is useful not only for managers interested in maximizing the value provided to consumers who are served by the AI, but also for researchers interested in uncovering the sociological and psychological underpinnings of the tension that accompanies this experience.

\section{Future Research on the AI Data-Capture Experience}

Sociological research questions. Future research should investigate how sociocultural forces affect feelings of exploitation in data-capture experiences. People from poorer childhood backgrounds have a lower sense of control than those from wealthier ones (Mittal and Griskevicius 2014), and collective self-construal is associated with a lower desire for choice freedom and control (Bernthal, Crockett, and Rose 2005; Markus and Schwartz 2010). Thus, both consumers' socio-economic status (Research Question 1A, or RQA1, see table 1) and prevailing cultural norms (RQA2) could influence consumers' propensity to feel and be exploited by AI. Other factors, such as education, political orientation, gender, and race (RQA3) could be examined using an intersectionality lens (Crenshaw 1989).

Future research should also explore how the cultural-cognitive, normative, or regulatory legitimacy of AI changes over time to influence consumer reactions to data-capture (Acquisti, John, and Loewenstein 2012; Humphreys 2010), particularly in light of AI's rapid diffusion in the marketplace. For example, researchers could study how and when increasing levels of familiarity with AI may reduce consumer sensitivity toward exploitation (RQA4). 
Psychological research questions. An interesting avenue for future research consists of exploring the role that psychological processes play in interpreting AI data-capture experiences as exploitative. For example, researchers could study the role of motivated reasoning (Kunda 1990) in shaping consumer affective reactions to data-capture experiences (RQA5): strongly held goals may motivate consumers to accept greater risk of exploitation when the $\mathrm{AI}$ is seen as a conduit to goal completion, mitigating negative emotional responses.

Other important open questions concern how the source and type of data used by the AI affect its potential to exploit. For example, an AI-enabled device that is constantly listening to biometric data could, over time, become paradoxically less invasive than one that listens only when activated (Turkle 2008). Complementing recent scholarship on the consequences of personal quantification (Etkin 2016), future research should address how the frequency of datacapture (e.g., intermittent versus continuous) affects perceived exploitation (RQA6). As another example, information about the physical environment, such as that acquired by a smart refrigerator, may be less likely to generate feelings of exploitation than information about the self, such as that collected by a fitness tracker (RQA7).

Feelings of exploitation may also differ based on the physical context of consumption (RQA8). Current attempts by companies like Amazon or Google to redefine the family home as a space accessible to corporations, rather than a private space may attenuate or exacerbate these feelings. Similarly, physical features of the environment where data collection takes place may differently trigger concerns about exploitation; for example, crowded environments lead to a loss of perceived control, perhaps decreasing willingness to provide data. Concerns about exploitation may also differ based on the device used to interact with AI (RQA9), as research has 
shown that consumers are more likely to self-disclose when using smartphones versus PCs (Melumad and Meyer 2020).

Finally, when consumers cannot or do not want to forego the benefits of data-capture, psychological reactance towards AI may manifest in adversarial user behaviors, as suggested by the experience of Danielle relayed above. Future research can explore the factors that lead consumers to respond to feelings of exploitation with behaviors like sabotaging AI by disabling sensors' inputs, intentionally providing false data by creating fake user profiles, or adopting antisurveillance outerwear to confuse the algorithms controlling facial recognition systems (RQA9).

\section{The AI Classification Experience}

Firms leverage the predicting capability of AI to create ultra-customized offerings and maximize engagement, relevance, and satisfaction (Kumar et al. 2019). Sophisticated algorithms consider a wide variety of information, including the characteristics of both current and past consumers. For example, Netflix uses AI to offer personalized movie recommendations based not only on individuals' past viewing history and that of other viewers, but also contextual information such as day of the week, time of day, device, and location (https://bit.ly/2YXrvia); Netflix even uses AI to select videoframe thumbnails that can increase subscribers' likelihood to click on a specific show (https://bit.ly/3dl7TtB). Even though prediction interfaces use individual and contextual information, they often refer to information related to other users either explicitly, by mentioning others when framing recommendations-Amazon noting "customers who bought this also bought"- or implicitly, by organizing recommendations in terms of communities of users or taste niches_-Amazon Prime drawing attention to movies for "period drama fans." As consumers are often unaware of the workings of algorithms, they may infer that these recommendations are based on being classified as a certain type of person. Such inferences are 
amplified by the human tendency for categorical thinking in person- and self-perception (Turner and Reynolds 2011). For example, consumers engage in categorical inference making when they are served behaviorally targeted ads: they attribute the ads they receive to the advertiser labelling them as a person with specific tastes (Summers, Smith, and Reczek 2016). We conceptualize the classification experience as one in which AI-enabled personalized predictions are perceived as the result of being classified as a certain consumer type.

Classification experiences can be positive because they lead consumers to feel deeply understood, either objectively or subjectively. For example, consumer categorizations can be valuable to affirm the self: personalized offers that indicate membership in an aspirational group may help consumers satisfy identity motives when they are perceived as social labels (Summers et al. 2016). Framings based on other users, such as "People who like this also like," makes recommendations more persuasive than those based on the product, such as "Similar to this item" (Gai and Klesse 2019), further suggesting that the experience of feeling classified by AI as a certain type of person is often positive. These findings resonate with research demonstrating the psychological benefits of group membership (Reed et al. 2012; Turner and Reynolds 2011). However, classification experiences may also lead consumers to feel misunderstood when they perceive AI as having inaccurately assigned them to a group or as having made biased predictions based on group assignment. At the societal level, classification by AI is linked to a dystopic narrative in which access to resources and freedom is restricted for some groups.

\section{Sociological Context: The Unequal Worlds Narrative}

Classification experiences do not exist in a sociological vacuum but are shaped by popular myths. Science-fiction stories such as Neill Blomkamp's Elysium have routinely imagined deeply divided police states in which the ruling class draws on algorithms to sustain a 
regime of inequality and fear. Sociological scholarship on the politics of algorithms (Seaver 2019) has also drawn on this popular imagination to theorize AI in the context of rationalization and quantification (Porter 1996), automated inequality (https://bit.ly/37N2Wsk), uneven information landscapes (Eubanks 2018), and the historical rise of "algorithms of oppression" (Noble 2018) or "weapons of math destruction" (O’Neil 2016). Emphasizing the intersectionality of race and gender with antisemitism, poverty, unemployment, and social class (Crenshaw 1989), these investigations of AI's potential for social classification are particularly insightful. AI is feared to privilege whiteness and undermine the identity projects of minorities (https://bit.ly/2NtKVWz). This contention is consistent with research on the market (bio)politics of race, which has consistently shown the inherently discriminatory potential of marketized representations of culture and ethnicity; it is also supported by economic critiques that warn against the monopolization of information by a centralized system (Hayek 1945; Polanyi 1948). Consider Google's corporate mission to “organize the world's information.” From an unequal-worlds perspective, such a statement is far from politically neutral but exemplifies the operation of seemingly benign appeals to data automation and quantification in a market that sanctions the production of biased information. In such an ideological system, the designers of an AI-enabled college application software, for instance, may be convinced that AI can help combat human selection bias. Yet, because "algorithms that rank and prioritize for profits compromise our ability to engage with complicated ideas" (Noble 2018, 118), the resulting AI experience may not only reduce the complex experiences of targeted marginalized populations to a set of more simplified sociodemographic attributes or stereotypes; when admissions officers use such system, they may also unintentionally expose marginalized applicants to experiences of racial profiling, misrepresentation, and economic redlining. Likewise, problems can arise when AI is 
used to decide whether a consumer is worthy of borrowing money from a bank. Although algorithms may make the selection process more efficient, they can also systematically exclude consumers who live in a neighborhood with higher credit defaults (https://bit.ly/2YSyfhd). The realization that AI can result in racial and social groups experiencing discrimination is an important backdrop for a psychological analysis of consumers' feelings of being misunderstood.

\section{Psychological Perspective: The Misunderstood Consumer}

Classification experiences are characterized by an underlying tension between feeling understood and misunderstood. Consumers can feel misunderstood because of perceived incorrect classification, discriminatory use of classification, or a combination of the two. First, consumers are likely to feel misunderstood when they perceive the identity implied by the AI's output as incorrect, either because it is factually inaccurate or because it is based only on one identity, whereas most individuals identify with a host of personal and social selves (Oyserman 2009). Identity-based consumer behavior is often the result of a negotiation between belonging and uniqueness motives playing out across this constellation of identities (Chan, Berger, and Van Boven 2012). In situations where AI predictions are perceived to be driven by the consumer's membership in a group, uniqueness motives may become relatively more salient. When this happens, group identity appeals may backfire if they are believed to threaten individual agency (Bhattacharjee, Berger, and Menon 2014). This negative response is especially likely when the consumer perceives the identity assigned to them by the AI as non-central or dated, as in this excerpt from a post (Spotify Community 2019, https://bit.ly/2Yg2oIq):

"The recommendations $\mathrm{s} * \mathrm{ck}$ :

- Listened to a few anime covers, now all my "Discover Weekly" is filled with disgusting covers. I'm trying to "not like" all of them, but it doesn't work (...). I've stopped listening to rock years ago and still get rock recommendations". 
From this consumer's perspective, AI seems to have decided that they like anime covers and rock, putting them in a category that they reject or do not see as capturing their multi-faceted and evolving self. The consumer is frustrated not only with being misunderstood by the AI, but also with their perceived inability to alter such misunderstanding.

Second, consumers may also feel misunderstood when they fear AI is using a social category in a discriminatory way to make biased predictions about them. This is particularly problematic in contexts where these predictions may enhance consumers' vulnerability because they restrict access to marketplace resources (Hill and Sharma 2020); for example, easily accessible digital information such as registering on a webpage is increasingly used by fintech companies to predict individuals' payment behavior and defaults, and therefore judge their creditworthiness (Berg, Burg, Gombović, and Puri 2020). Consider this tweet by a software developer, David Heinemeier Hansson (https://cnb.cx/2CsTtuJ):

“The @ AppleCard is such a f*ing sexist program. My wife and I filed joint tax returns, live in a community-property state, and have been married for a long time. Yet Apple's black box algorithm thinks I deserve 20x the credit limit she does..."

This consumer is frustrated because of the AI's inability to understand the reality of his household's finances, but he is also morally outraged because he thinks that his wife's denial of credit was based on her gender. Perception of vulnerability such as this can have negative effects on the self-concept. This can occur, for example, when minorities whose financial choices are systemically restricted then frame the self as "fettered, alone, discriminated, and subservient" and experience reductions in self-esteem and self-efficacy (Bone, Christensen, and Williams 2014).

Consumers can also experience a combination of the two ways of feeling misunderstood mentioned above: they can be incorrectly assigned to a category and this incorrect assignment 
can exacerbate existing limitations to choice and freedom for vulnerable consumers. Facial recognition software, for instance, uses AI to identify a person by comparing a target facial signature to databases of known images. The range of applications of such software includes mobile devices (e.g., Apple's Face ID), social media (e.g., Facebook's tagging feature), and physical spaces (e.g., airport customs officials). Whereas a failure of Apple's Face ID to start one's own device may result in frustration, incorrect identification in other applications may result in ethical violations. Consider the open letter to Amazon CEO Jeff Bezos written by the Congressional Black Caucus on the potential danger caused by Amazon's facial recognition tool, Rekognition (https://bit.ly/2BaSkHL):

"communities of color are more heavily and aggressively policed than white communities (...) We are seriously concerned that wrong decisions will be made due to the skewed data set produced by what we view as unfair and, at times, unconstitutional policing practices" (Congressional Black Caucus 2018).

In a subsequent test, Rekognition indeed incorrectly matched 28 current members of the U.S. Congress with people who had committed a crime, and the false matches were disproportionately for people of color (https://bit.ly/3fIPY1t). In June 2020, Amazon suspended police use of this technology (https://on.wsj.com/2AVqj72). We next examine how managers can understand and address the risk of consumers feeling misunderstood.

\section{Managerial Recommendations: Understanding the Misunderstood Consumer}

Organizational Learning. How does an organization best surface and address accounts of biased treatment? Unlike data capture errors, which may be very lagged and hard to correct in real-time, classification errors produce signals soon after they occur. They also happen in very different parts of an organization. For instance, if an AI system has rejected a college applicant due to a biased algorithm, it is likely to assume that such a classification error will almost 
immediately surface in the college's admissions department and data - data which, in turn, might be used to structure the next round of applications.

Owing to this data dependency, organizations may not even be aware that a given distribution or algorithm is the result of a classification error. In the case of a college, for instance, classification might be regarded as a natural outcome of the competitive process by those in charge of managing the admissions process. Hence, unlike data-capture failings which require the specific attention of software programmers and data scientists, addressing classification errors requires organizations to focus on marketing and consumer-facing departments and to examine whether these departments' databases or, even more abstractly, the organizations' taken-for-granted understanding about whom they have served and should serve and why, carry entrenched social and racial biases.

Organizations must thus focus on learning about the specific biases that might be present in their own algorithms and processes in order to root them out. In the U.S., the Algorithmic Accountability Act of 2019 would require companies to assess their AI systems for "risks of 'inaccurate, unfair, biased, or discriminatory decisions' and to 'reasonably address' the results of their assessments" (MacCarthy 2019). Rather than reacting to a changing regulatory landscape, firms should proactively collaborate with technology experts and thought leaders in computer science, sociology, and psychology to develop and conduct such audits. Firms can then share both their audit processes and outcomes, for example, by engaging in lobbying efforts to ensure that regulations passed in the name of consumer welfare include meaningful and technologically appropriate provisions to protect consumers from discrimination.

Experience Design. Organizational learning should be leveraged in the design phase to develop AI classification experiences where consumers' likelihood of feeling misunderstood is 
minimized. Managers could build on the insights gained from listening to consumers who felt they were classified based on narrowly defined identities to experiment with diversifying and broadening the content they provide and to propose products that are dissimilar from the user's preference profile. Indeed, Spotify has launched Taste Breakers, a function that introduces customers to music to which they normally do not listen. Similar attempts at "bursting the bubble" are especially important in light of the possibility that, by optimizing information provision based on past choices, AI both ignores long-term goals that do not reflect short-term behaviors (André et al. 2018) and increases attitude extremity and polarization (Flaxman, Goel, and Gao 2016). Firms could also address feelings of being misunderstood by asking consumers to validate AI-based inferences. As greater user participation in the implementation of algorithms increases satisfaction in decision support systems (Wierenga and Oude Ophuis 1997), periodically offering consumers the opportunity to update the AI's view of the self could similarly reduce potential frustration.

Managers can build on the insights gained from listening to discriminated consumers to design both de-biased and anti-bias AI experiences that foster an inclusive society rather than perpetuate inequality (Green and Viljoen 2020). To do so, managers should institute protocols that swiftly react to any bias uncovered in regular audits of the AI systems for the presence of discrimination (Zou and Schiebinger 2018). Organizations should also diversify their hiring to include more members of social minority groups and ensure that their culture and processes represent diverse viewpoints at all stages of the design of AI classification experiences. For example, advocates for reducing bias in AI have suggested that technology companies must employ more individuals with disabilities to learn how to eliminate disability bias from AI (https://on.ft.com/2P0iws9). The tension between feeling understood and misunderstood in 
classification experiences represents a learning opportunity not only for managers but also for researchers.

\section{Future Research on the AI Classification Experience}

Sociological research questions. Researchers can unpack the influence of sociocultural factors on classification experiences. Values and ideology may change consumers' interpretation of personalized predictions, as those who are more aware of the sociohistorical context of discrimination by algorithm (Noble 2018) and belong to marginalized groups should also feel more vulnerable to AI's potential to restrict access to resources and freedom (RQB1).

Drawing on research that examines the ways in which powerful institutions define the consumer (Borgerson 2005), future work should also explore the social classifications that firms routinely inscribe into their AI solutions, such as certain consumers' habits, norms, and preferences. This lens can usefully unearth the existence of ideological blind spots in the models employed by firms and examine the uneven landscapes of experiences and choices that these models produce once consumers are subjected to them (RQB2).

Psychological research questions. Future research should explore how psychological processes affect the extent to which consumers feel misunderstood in classification experiences. Open questions concern lay beliefs about how AI classifications are made (RQB3) and whether certain inferred categorizations are especially likely to induce feelings of being misunderstood (RQB4). For example, research on attributional ambiguity suggests that stigmatized consumers may attribute AI classifications to bias towards their group identity on the part of the algorithm rather than to other causes (Crocker and Major 1989).

More generally, feeling misunderstood may be more likely in contexts where consumers value uniqueness over belongingness (RQB5). For example, patients are reluctant to use medical 
AI due to a sense that it cannot account for their unique characteristics and circumstances as well as human doctors can (Longoni, Bonezzi, and Morewedge 2019). The nature of the task may also have an influence (RQB6): consumers tend to exhibit greater aversion towards algorithms for subjective tasks, which are based on personal opinions or intuitions, than for objective ones, which are based on quantifiable and measurable facts (Castelo, Bos, and Lehman 2019). Given that many AI systems learn and predict subjective taste, negative reactions to inferred classification might be especially common.

\section{The AI Delegation Experience}

A delegation experience is one in which consumers involve an AI solution in a production process to perform tasks they would have otherwise performed themselves. These tasks can be decisions, such as when Google Assistant, at the consumer's request, calls a hairdresser, matches the consumer and the hairdresser's calendars, and uses a human-like voice to book an appointment. They can also be actions in the digital world, like those performed by Smart Compose, a writing tool that uses AI to help consumers write emails. Finally, they can be actions in the physical world, as when the Nest Thermostat learns the consumer's temperature preferences and programs itself to fit them.

By not having to engage in the tasks the AI performs on their behalf, consumers in delegation experiences can feel empowered in two distinct ways. First, consumers can spend their time and effort on activities they find more satisfactory and meaningful: they can work less and enjoy the positive effects of leisure (Fishbach and Choi 2012), or they can work better and enjoy greater happiness by delegating extrinsically motivated tasks to AI, keeping intrinsically motivating tasks for themselves (Botti and McGill 2011). Second, consumers can focus on activities that are more suitable to their skills and leave to AI those on which they underperform; 
this way, they can enhance self-efficacy, or the perceived ability to master the environment in order to produce a desired outcome (Bandura 1977).

Given the empowering benefits of delegation experiences, managers may be tempted to offer consumers increasingly more opportunities to delegate tasks to AI. However, like the case in which the mere presence of too many choice options can reduce consumers' satisfaction (Iyengar and Lepper 2000), the mere presence of too many delegation opportunities may lead to aversive consequences. We next examine this tension between the possibility of AI to empower and replace consumers both at the societal and individual level.

\section{Sociological Context: The Transhumanist Narrative}

To analyze the negative aspects of delegation brought about by the possibility of being replaced from a sociological perspective, it is helpful to examine how the heuristics that have guided consumers' interactions with AI tools have been historically understood in popular culture.

We draw on widespread science-fiction and social science literature that falls into the so-called transhumanist genre. From Fritz Lang's Metropolis to Isaac Asimov's I, Robot, and from Mary Shelley's Gothic monster Frankenstein to James Cameron's Terminator, countless cautionary tales have profiled the dangers of reimagining human capabilities and characteristics through a technological mirror. Specifically, these stories fuel the view that, by transcending human limitations, technology eventually molds into an omnipotent super-human and subsequently unfolds under the ideal of technological perfection-implying new standards.

Critics of this transhumanist perspective (Sassen 2014, 23) have linked AI to "new logics of expulsion" and economic redundancy that arise as AI approaches aging, health, productivity, and other domains through the transhumanist lens of limitless performance rather than standard levels of wellbeing or productivity. These observers fear that AI solutions will result in 
significant unemployment, leading to a rapid increase in surplus populations whose AI experience will be their de-facto removal from the productive aspects of the social world.

In the social science literature, this super-human narrative is paralleled in the Computers Are Social Actors (CASA) and Human Computer Interactions (HCI) paradigms, according to which the same heuristics used for human interactions are mindlessly applied to computers (Grudin 2017; Nass and Moon 2000). Since the 1960s, technology companies have periodically imbued the productive aspects of AI technology and machine prototypes with mythic narratives emphasizing that science and technology will eventually accomplish human immortality.

These transhumanist ideas, which emphasize technological progress as an unstoppable force that alters human experience (Hayles 1999), have been deeply inscribed in contemporary AI experiences, from the promise that the Roomba vacuum cleaner could perform tasks more effectively than humans to the promise that 23andMe could help in the creation of genetically optimized offspring. Yet, the transhumanist preoccupation with Promethean aims underlying many contemporary AI experiences also leads to systemic dehumanization (Fukuyama 2002; Habermas 2003). For instance, human perception of mastery over the environment depends on not being subject to unilaterally imposed specifications. A world in which our interactions with machines are fueled by transhumanist ideals will endorse a glorification of capitalism's endless creativity while treating destructiveness and human replacement as normal costs of doing business (Schumpeter 1942). Further, an economic obsession with "perfection," "progress," and "efficiency," will promote the rise of the "useless class" (Harari 2017), individuals whose skills are no longer developed or demanded, and fundamentally erode democracy and social justice.

\section{Psychological Perspective: The Replaced Consumer}


Delegation experiences can help consumers feel empowered but can also raise concerns about being replaced. The mere recognition of the capability of AI to substitute for human labor can be psychologically threatening for three main reasons. First, people have a strong desire to attribute consumption outcomes to one's own skills and effort (Bandura 1977; Leung, Paolacci, and Puntoni 2018). Research on human-computer interaction has shown that humans often see computers as disempowering because they deprive humans of the sense of accomplishment related to an activity, so much so that they tend to credit themselves for positive outcomes and blame computers for negative ones (Moon and Nass 1998). In contexts where products are crucial to the experience of having an identity as a certain type of person (Reed et al. 2012), delegation experiences may feel tantamount to cheating. In the fishing industry, for example, AI can help anglers be more effective in location and bait decisions. However, in the words of biologist Culum Brown (https://econ.st/2ALoOZf):

"It is really getting kind of unfair. If you are going to use GPS to take you to a location, sonar to identify the fish and a lure which reflects light that humans can't even see, you may as well just go to McDonald's and order a fish sandwich."

Second, outsourcing labor to machines prevents consumers from practicing and improving their skills, which can negatively influence self-worth and contribute to a satisficing tendency by which individuals settle for a level of engagement that is just good enough. Consider the experience of journalist John Seabrook. While composing an email to his son, Seabrook started the sentence "I am p...", intending to write "I am pleased," but resolved to instead accept the suggestion of Google's Smart Compose "I am proud of you." After hitting Tab to accept the suggestion, Seabrook muses (https://bit.ly/3fX7YFE):

"What have I done? Had my computer become my co-writer? That's one small step forward for artificial intelligence, but was it also one step backward for my own? (...) I'd always finished my thought by typing the sentence to a full stop, as though I were defending humanity's exclusive right to writing, an ability unique to our species. I will 
gladly let Google predict the fastest route from Brooklyn to Boston, but if I allowed its algorithms to navigate to the end of my sentences how long would it be before the machine started thinking for me?"

Finally, outsourcing tasks to AI can lead consumers to experience a loss of self-efficacy. Self-efficacy is an antecedent of personal control (Bandura 1977), and it is heightened when individuals are actively engaged in creative tasks (Dahl and Moreau 2007; Norton, Mochon, and Ariely 2012). The notion that being productive is a way to feel in control is consistent with findings showing that consumers who experience low control attempt to re-establish it by choosing products that require higher, versus lower, effort to achieve a desired outcome (Cutright and Samper 2014). In line with this view that delegation can lead to loss of control, drivers involved in GPS-related accidents tend to describe their experience in terms of surrendering control to the machine. Take for instance the tourists who drove their car into the ocean trying to reach an Australian island and recounted that the GPS "told us we could drive down there (...) It kept saying it would navigate us to a road" (https://bit.ly/3dprF7q).

The tension between being empowered and replaced is relevant from a managerial perspective because AI designers need to decide how delegation experiences should be designed to protect self-efficacy and self-identity. We next discuss potential recommendations emerging from the sociological and psychological analysis of this tension.

\section{Managerial Recommendations: Understanding the Replaced Consumer}

Organizational Learning. Companies can start by learning how to include the human desire for self-efficacy into the corporate discourse in two main ways. First, they can collaborate with family scholars, workplace psychologists, and health sociologists to understand the consequences of human replacement by AI. Second, they can engage in conversations with consumers to gain greater insight into which activities they prefer to reserve for themselves 
versus delegate to AI, and how these preferences shift across consumer, identity, and task. Organizational design and personnel policies can facilitate this learning by ensuring that the insights gained through external collaborations and consumer listening permeate the firm's culture, especially in the more technical functions. For instance, technology firms could hire experts in creativity such as artists, artisans, or chefs into AI-focused experience design roles.

Firms could also learn from organizations that protect, support, and enhance abilities that are conceived as intrinsically "human" and on which individuals remain superior to machines, such as performing complex tasks, adapting to changes, using emotional intelligence, and offering nuanced judgments in unstructured environments (https://bit.ly/382Yh5J). Thus, collaborations with museums, theatres, and universities' humanities departments can inspire managers to understand how AI can preserve, rather than subvert, traditional human values such as creativity, collaboration, and community (Brunk, Giesler, and Hartmann 2017).

Experience Design. The learning achieved in the previous phase should serve as the bedrock on which AI designers decide how to model delegation experiences in order to protect self-efficacy and self-identity (Leung et al. 2018). Division of labor in production processes can have positive effects on demand if consumers feel they have the competence to make sound decisions about the tasks they decide to engage in (Fuchs, Prandelli, and Schreier et al. 2010). Thus, AI can be conceived as a platform to enhance intrinsically human skills and values. In the medical domain, for example, the benefits of AI-powered surgical robots for consumers depend on the way in which the surgeon's input and supervision is designed. Surgical robots are more precise than humans, can make quicker and more reliable diagnosis, and are more democratic and cost-efficient than current systems because they can intervene outside of hospitals. Still, the structure of surgeons' supervision of the robots is central to the success of this technology, both 
because patients are afraid of being operated on by a machine and because the AI cannot yet outperform human doctors in some critical technical and social skills (https://bit.ly/2AVtHyM).

Given the link between self-efficacy and control, the design of delegation experiences could also consider the extent to which consumers make choices and initiate actions (Carmon et al. 2020; Schmitt 2019). For example, autonomous vehicles should allow for the customization of peripheral features to avoid perception of lack of control (André et al. 2018), and digital assistants in computer games should not be anthropomorphized to preserve the players' sense of autonomy (Kim, Chen, and Zhang 2016). The classic finding that cracking fresh eggs into a premade Betty Crocker cake mix might be enough to re-establish consumers' self-worth and improve adoption (Marks 2005) still resonates in the context of AI, as the amount of control needed by consumers to reduce a self-efficacy threat can be quite small. For instance, offering users the possibility to correct an algorithm's output, even if only slightly, is sufficient to increase their likelihood of using the superior, although imperfect algorithm, rather than the preferred, inferior human forecast (Dietvorst, Simmons, and Massey 2016).

\section{Future Research on the AI Delegation Experience}

Sociological research questions. The extent to which consumers feel replaced by AI is likely shaped by cultural narratives about AI and by the shared understanding of what it means to be productive. Activities that tend to be perceived as if they ought to fall to human skills and competence (Castelo et al. 2019) should be more likely to spur feelings of being replaced (RQC1). Consider a self-driving car choosing between stopping and crossing at an intersection versus choosing between swerving and killing one pedestrian or not swerving and killing several pedestrians (Bonnefon, Shariff, and Rahwan 2016): the car's passenger may feel more replaced in the latter case, which involves a moral dilemma, than in the former case, which involves a 
mechanical decision. Further, feeling replaced by AI may alter the social or moral acceptability of behavior and its likelihood of occurrence (RQC2); for example, self-protective behaviors appear more moral when adopted by autonomous vehicles than by humans (Gill 2020). Perceptions of what ought to fall to human competence may, however, shift rapidly as AI technology advances (RQC3).

Negative reactions to feeling replaced by AI are likely to differ across consumption contexts (RQC4). Future research can explore whether delegation to AI is less threatening in categories where consumers are already familiar with recommendation agents (e.g., entertainment), are less confident in their own preferences (e.g., finance), are open to experimentation (e.g., food), and can trust the AI brand (JWT Intelligence Wunderman Thompson 2016). As AI encroaches on an ever-expanding set of human activities, researchers could also explore whether feelings of replacement in one domain could motivate consumers to seek control in others (RQC5); for example, will consumers engaged in daily delegation experiences become more controlling in non-consumption domains, such as politics?

Psychological research questions. Future research should examine when the psychological processes that lead to the experience of feeling replaced by AI are activated, as well as the consequences of such feelings. For example, is the extent to which delegation experiences are perceived as a threat to the self a function of whether consumption is motivated by instrumental or symbolic motives (RQC6)? Preferences for human over robotic labor tend to be stronger in symbolic consumption contexts (Granulo, Fuchs, and Puntoni 2020), and the same might apply in the case of one's own labor: whereas for most consumers being replaced by Nest in setting their home's temperature is likely perceived as desirable, for those whose identity is tightly linked to house-keeping, this replacement may be seen as aversive (Leung et al. 2018). A 
related topic pertains to how a focus on the outcome or on the process differently influences perceptions of delegation experiences (RQC7). Products are means to ends, but the process of consumption, as well as the performative display of skill and knowledge, can often be intrinsically valuable to consumers (Reed et al., 2012). For example, for a person who is nurturing an angler's image, the extent to which AI-driven fishing tools are seen as selfthreatening may depend on the reference group's norms about task delegation and the relative importance placed on the outcome (e.g., a bigger catch) or the process (e.g., finding a good location for fishing).

When self-efficacy and control are threatened in delegation experiences, consumers may employ different strategies to restore them, including increasing agency and seeking structure and boundaries (Landau et al. 2015). Thus, future research can explore whether and when consumers who feel replaced opt to constrain the involvement of the AI in production processes (RQC8) to both reaffirm self-efficacy by increasing their own role in these processes and to seek structure by physically and/or mentally bounding AI features. This deliberate limitation of the AI is similar to situations where consumers restrict the usage experience with smart objects to the most basic and least innovative forms of interaction (Hoffman and Novak 2018).

\section{The AI Social Experience}

AI's capability for engaging in reciprocal communication produces what we term a social experience. We focus on two types of social experiences: when consumers know at the outset that the interaction partner is an AI, such as when using a voice assistant like Apple's Siri, and when they interact with an AI representing an organization without necessarily knowing initially that it is non-human, such as when receiving customer service from an automated chatbot. In both cases, consumers have a social interaction with AI as part of a consumption experience 
where the end goal is not the AI interaction. We do not focus on two other types of interactions: when consumers are never aware that the interaction partner is a simulated person (because the experience would be perceived as a normal social interaction) and when consumers interact with the $\mathrm{AI}$ as an end in itself, as in the case of a robotic pet.

Social experiences are beneficial when consumers can find in AI a vehicle for information exchange that connects them with the firm in a natural way. This often happens when anthropomorphic features are incorporated in AI-enabled products: anthropomorphic cues increase trust towards self-driving cars (Waytz, Heafner, and Epley 2014) and reduce perceived risk when consumers are in a position of power (Kim and McGill 2011), as when they interact with a virtual assistant. More generally, developments in social robotics are making it possible to create comfortable and even emotionally meaningful AI-powered service interactions (van Doorn et al. 2017). Social AI experiences are beneficial also because they can be more efficient, especially in situations where the alternative to AI is not a human interaction but the absence of any interaction: AI provides consumers access to firms through "conversational commerce."

Despite these advantages, social experiences may also alienate consumers. Negative consumer reactions to simulated social interactions can go well beyond the occasional disappointment as these interactions emerge in a rich cultural context where they can easily trigger societal and individual concerns with unbalanced intergroup relations and discrimination.

\section{Sociological Context: Humanized AI Narrative}

The sociological starting point for social experiences is the widespread cultural fascination with humanized machines (Adam 1998; Haraway 1985; Suchman, Roberts, and Hird 2011)specifically, the preference for machines that emulate the human body and traits. For instance, a well-noted trope in science-fiction is the pursuit of the perfect artificial woman 
(https://bit.ly/3eiPA9P), a male fantasy of a beguiling, seductive, and sexually obliging object (https://bit.ly/3fFJnF6). These female robots or "gynoids" are routinely imagined as "basic pleasure models" in Philip K. Dick's Blade Runner and sex workers in Michael Crichton's Westworld, or they are traded like used cars in Steve de Jarnatt's Cherry 2000.

This cultural preference for humanized AI is amplified by the widespread use of anthropomorphized chatbots and voice assistants in contemporary AI markets. Humans are less open, agreeable, conscientious and self-disclosing when they interact with AI versus humans (Mou and Xu 2017); however, these perceptual barriers can be overcome, and intimate experiences can be accomplished, when AI products feature human characteristics, behaviors, and language, thus ultimately becoming "artificial besties."

Nevertheless, in this narrative, AI companies that strive for greater human touch cannot ignore that AI products and services modelled as "obliging, docile and eager-to-please [human] helpers" often contribute to the social alienation of particular groups in society (West, Kraut, and Chew 2019, 104). Consistent with this finding, from the iconic robot character Maria in Metropolis to Apple's Siri, patriarchal norms and preferences embedded in seemingly benign AI experiences have the potential to engage only certain types of users, such as white men, while alienating others, such as women and racial minorities (Adam 1998; Hayles 1999; Haraway 1985).

From this perspective, an instance such as Siri's earlier programming to answer to users who say, "You're a slut" with "I'd blush if I could" (https://bit.ly/2YU5OQa) would not just be evidence of biases within the male-centric technology sectors and of the fact that AI mirrors the misogyny concealed in language patterns; it is also diagnostic of the tendency to undermine AI's social and inclusive possibilities. By collapsing dualistic categories such as male versus female, 
for instance, social experiences could at least partially ease the social isolation brought about by misogynous and racial stereotyping. Yet, because anthropomorphized AI typically reproduces such dualistic categories to maximize consumer engagement (e.g., men who treat women as assistants, women who are more assistant-like), social experiences have the potential to exclude rather than include and to alienate, rather than connect, certain groups of consumers.

\section{Psychological Perspective: The Alienated Consumer}

AI social experiences have the power to bolster consumer-firm relationships but also to alienate consumers. We identify two main types of alienation engendered by AI social experiences. The first type can occur with any failed automated customer service, as exemplified in this exchange between a customer and chatbot UX Bear (https://bit.ly/2YuYAD1):

Bot: "how would you describe the term "bot" to your grandma?" User: "My grandma is dead".

Bot: "Alright! Thanks for your feedback (Thumbs up emoji)".

This type of alienation may explain consumers' widespread resistance to replacing humans with machines (Castelo et al. 2019; Leung et al. 2018). For example, consumers report feelings of discomfort when interacting with "social robots" in service contexts (Mende et al. 2019), and customers' responses in a field study became markedly more negative when they were informed in advance that their interaction partner would not be a human (Luo et al. 2019). The potential of AI to trigger alienation is also evident in the resurgent interest in social connections that are unmediated by technology, such as authentic consumption experiences (Beverland and Farrely 2010) and more personal marketing exchanges (van Osselaer et al. 2020).

The second type of alienation results from AI's failure to interact successfully with specific groups of consumers. For example, the UK government's reliance on AI to handle claims to its social security program led to experiences like that of Danny Brice, who has 
learning disabilities and dyslexia, and describes his attempts to use the automated Universal Credit program as follows (https://bit.ly/3dEhUCt):

"I call it the black hole (...) I feel shaky. I get stressed about it. This is the worst system in my lifetime. They assess you as a number not a person. Talking is the way forward, not a bloody computer. I feel like the computer is controlling me instead of a person. It's terrifying."

Thus, AI can exacerbate existing barriers that prevent specific social groups from accessing essential social services, reinforcing societal inequity. Another example of how alienating social experiences can feed inequality is chatbots programmed without considering how existing discrimination in society may affect their operation, such as when Tay, a Twitter bot by Microsoft, began offering white supremacist answers to users soon after its launch, with exchanges like the following (https://bit.ly/2Nw0ZHu):

User: "What race is the most evil to you?"

Bot: "Mexican and black".

The cultural narratives of oppression and discrimination underlying this example are even more apparent in the context of personal virtual assistants. Journalist Sigal Samuel recounts working on a piece about sexist AI (https://bit.ly/3fFs7zM):

"I said into my phone: "Siri, you're ugly." She replied, "I am?" I said, "Siri, you're fat." She replied, "It must be all the chocolate." I felt mortified for both of us. Even though I know Siri has no feelings, I couldn't help apologizing: "Don't worry, Siri. This is just research for an article I'm writing!" She replied, "What, me, worry?"

Alienating social experiences such as the one above, in which women face societal pressures around their appearance, may lead consumers to denigrate and belittle the AI, similar to situations where individuals derogate outgroup members in order to re-affirm self-esteem following an identity threat (Branscombe and Wann 1994). Dissatisfaction with a voice-enabled device might produce verbal responses that emphasize its artificial and worthless nature. The tendency to objectify others, and women in particular, is well-known (Fredrickson and Robert 
1997), and it should be stronger when the interaction partner is, in fact, an inanimate entity, however human-like its communication; indeed, conversational failures lead consumers to express more frustration with AI when it has a female rather than a male voice (Hadi et al. 2020). This denigration of AI risks translating into behaviors that reinforce inequality.

As technology enables companies to create automated interactions that are more and more like real human interactions, a new set of ethical issues confront both organizations and marketing researchers, as we discuss in the next sections.

\section{Managerial Recommendations: Understanding the Alienated Consumer}

Organizational learning. To effectively manage AI social experiences, companies should learn how to acknowledge and accommodate the heterogeneity of human interaction styles and needs. To this aim, firms should collect information directly from consumers who have experienced alienation in their interactions with AI. In addition, firms can leverage technology to gauge and measure alienation (operationalized using measures like amount of stress in the customer's voice) in chats with AI service providers in order to develop generalizable insights about when alienation is most likely to occur. Firms should also interact with psychologists, sociologists, gerontologists, and other experts to learn about both causes and consequences of alienation.

Organizational learning should also ensure that definitions of anthropomorphism do not draw on and calcify harmful stereotypes about social categories and the way they interact. One way to do so is breaking with organizational cultural conventions that idealize AI as a passive and subservient humanized other by involving experts like linguists, critical theorists, and social psychologists who study the subtle ways in which stereotyping affects communication. For example, disseminating information throughout an organization about the potential societal 
consequences of exposure to subservient female AIs may shift AI designers away from using female names and voices as defaults (https://bit.ly/331YGEZ).

Experience Design. Based on the greater sensitivity emerging from organizational learning activities, firms can improve the design of AI social experiences. As timely and appropriate firm responses can do much to mitigate the harmful consequences of service failure (Hart, Heskett, and Sasser 1990), firms should work to increase the effectiveness of interactive AI applications to minimize the likelihood of alienation. Research shows that consumers respond positively when AI service providers personalize the interactions, for example by using the customer's name and explaining the reasons for malfunctions (Carmon et al. 2020). Relatedly, firms should also ensure easy and swift transitions from AI to human representatives when the interaction becomes difficult or aversive.

To avoid the perpetuation of harmful stereotypes, companies could also strive to develop AI that is less, rather than more, humanlike (Hadi et al. 2020); indeed, software developers have begun investigating the creation of gender-neutral voices (https://n.pr/2NibE8t). This requires a radical change in the mindset of many AI designers (and marketing academics), who often take it for granted that anthropomorphism fosters better relationships with customers (Kim et al. 2016). Organizations should also evaluate the potential consequences of using AI for access to basic social services for consumers like Danny. When AI is deployed to provide important welfare services, designers need to recognize the barriers that they can create for specific user groups, even when the technology has satisfied standard performance benchmarks.

Finally, instead of worrying solely about designing to improve human-AI interaction, firms could address alienation by considering how AI design can improve human-human interaction. Firms can design social experiences that help support what Epp and Velagaleti 
(2014) call "care assemblages" by connecting individuals to dear ones in ways that are reminiscent of popular social media strategies designed to foster and satisfy consumers' social goals (Epp, Schau, and Price 2014). Thus, companies could actively shift from understanding AI as a substitute for humans towards understanding $\mathrm{AI}$ as an interface that facilitates social connection (Farooq and Grudin 2016).

\section{Future Research on the AI Social Experience}

Sociological research questions. Consumers vary in the extent to which they hold antibias beliefs and are willing to take action to address bias in society (Ivarsflaten, Blinder, and Ford 2010). Those who are more concerned about AI fostering alienation may be particularly likely to reject the idea that AI can be a true social partner (RQD1). Cultural differences are also likely to influence the extent to which social experiences are perceived as alienating (RQD2). Asian consumers feel a stronger connection to both people and things than Western consumers, and, as a result, have shaped their social interactions with AI in more personal ways: AI social experiences in the West are mainly utilitarian and involve disembodied personal assistants, whereas those in the East involve human and animal-appearing robots that are assumed to serve and improve society (Belk, Humayun, and Gopaldas 2020).

If, over time, AI social experiences become commonplace, future research should explore their broader interpersonal and societal consequences (RQD3). Just as the synthetic and unrealistic nature of pornography has been accused of distorting the sexual expectations of teens (Owens et al. 2012), AI social experiences might increase the prevalence of sexist language if they trigger female objectification (Hadi et al. 2020). Researchers could also build on literature on intergroup relations, such as Haslam's (2006) theory of dehumanization, to investigate the conditions under which objectification of AI is more likely to occur (RQD4). 
Psychological research questions. An information processing perspective could shed light on how AI social experiences are interpreted and evaluated. The timing of disclosure that the interaction partner is, in fact, an algorithm may influence consumer response to social experiences (Luo et al. 2019), similar to the "change of meaning" that occurs when consumers realize that a message is meant to influence their behavior (Friestad and Wright 1994). Thus, alienation might be more likely to emerge if consumers question the company's intention to disclose the nature of the interaction partner (RQD5). Moreover, research on the effects of disclosure in word-of-mouth (Tuk et al. 2009) and product placement (Campbell, Mohr, and Verlegh 2012) shows that situational factors may influence consumer reactions via an effect on cognitive capacity; researchers can examine how these factors also affects alienation (RQD6).

Future research could also explore the role of brand equity (RQD7). As brand attachment influences consumer expectations and can shield companies from negative appraisals in ambiguous situations (Lee, Frederick, and Ariely 2006), stronger consumer-brand relationships may also insulate consumers from experiencing interactions with $\mathrm{AI}$ as alienating.

\section{Agenda for Future Research on Consumers and AI}

We developed a framework to structure our understanding of consumers' interaction with AI by defining and contextualizing the AI data-capture, classification, delegation, and social experiences using both sociological and psychological lenses. In this final section we go beyond these four experiences to identify additional future research questions in two areas: interrelationships between the four experiences and new AI experiences that may emerge along with new capabilities. These additional research questions are also included in Table 1. ---Table 1 about here---

\section{Interrelationships Between Experiences}


Although we discussed the four consumer AI experiences separately, our framework is not intended to suggest that they exist independently; on the contrary, these experiences could be seen as different aspects of the same customer journey and, as such, influence each other (Lemon and Verhoef 2016). An important avenue for future research is to explore where and how consumers' experience with one AI capability directly affects their experience with another AI capability (Giesler and Fischer 2018). For example, whether consumers feel served versus exploited in an AI data-capture experience is likely to impact a subsequent AI classification experience. Consumers who feel exploited may be more likely to worry about AI inappropriately using their personal data to regulate access to valued resources (RQE1). Similarly, intrusive datacapture requests might foster consumer alienation (RQE2); for instance, students who view an AI-enabled teaching assistant such as Packback.co as overly inquisitive might feel less included in the virtual classroom and less likely to participate in communal activities such as online discussion boards. Future research can also explore whether consumers are more likely to perceive an AI classification as benefiting them when they are asked to validate inferences made by the AI, turning a classification experience into a delegation one (RQE3).

Another avenue for research is related to the identification of additional ways in which AI experiences influence each other by uncovering shared theoretical foundations. For instance, the data-capture and delegation experiences share an emphasis on concerns about personal control as interacting with AI often involves giving up at least some control over personal data and production processes (RQE4). Similarly, classification and social experiences share an emphasis on concerns about self-identity, as interacting with AI often influences inferences about how AI understands the self and feelings of belonging (RQE5). Confirming the relevance of these theoretical perspectives, personal control and self-identity have been recognized as key concerns 
in the nascent literature on consumer AI (André et al. 2018; Belk et al. 2020; Carmon et al. 2020; Schmitt 2019). A search for shared theoretical foundations may stimulate academic research and help AI designers form a more holistic understanding of consumers' interaction with AI. For example, as consumers come to understand $\mathrm{AI}$ as an independent intelligence operating in the marketplace to whom they can delegate tasks and with whom they can interact, marketplace metacognition and social intelligence (Wright 2002) theory can be leveraged to better understand the theories consumers have about how AI "thinks" (its intentions, strategies, etc.) and how these lay theories influence how consumers respond to AI.

An integrated view of the four experiences will also maximize the value consumers see in organizations' investments into AI. Some companies find themselves in a "Catch 22" situation, where users need to reveal personally sensitive information for the company to provide valuable benefits but are unwilling to do so unless they can first experience such benefits (Grafanaki 2017). Based on an integrated understanding of AI consumer experiences, it may be possible to articulate and structure alternative customer journeys. For example, companies could provide an initial basic service requiring limited disclosure of personal information and later on offer the possibility to access an upgraded version that requires additional individual data. Thus, demands for data-capture could ramp up as the company is able to demonstrate the benefits that delegation brings to consumers (RQE6).

\section{Unchartered AI Experiences}

Our framework offers a parsimonious template to conceptualize how consumers navigate the disparate consumption contexts powered by AI, including social media, online shopping, and personal virtual assistants. In doing so, the framework identifies experiences relevant to a large variety of industries and products. However, additional consumer experiences that we did not 
examine are on the rise in specific industry sectors, and future research can examine both industry-specific experiences stemming from existing capabilities and new experiences stemming from emerging capabilities (Figure 1).

Although we theorized the production capability as leading to a delegation experience, this capability can also be used to develop an AI learning experience in the education industry. Knowledge and skill acquisition can be facilitated by letting AI personalize aspects of the learning process, such as producing tailored content and testing materials. Future research can examine how different aspects of the learning experience impact subjective and objective assessments of educational outcomes (RQF1). For example, the risk of engendering negative feelings of being replaced in delegation experiences may have a parallel in learning experiences: if an AI application makes it more challenging to internalize the outcome of the learning process, learning experiences might decrease satisfaction and motivation. This may be especially likely to occur when the learning content is relevant to one's identity: just like consumers tend to resist automation in identity-relevant consumption domains when it prevents the internal attribution of consumption outcomes (Leung et al. 2018), students may show reactance to AI applications that prevent them from attributing learning to their own talent and effort (RQF2).

Another avenue for future research is to relax some of our definitional boundaries to include a larger set of consumption contexts. For example, in our discussion of social experiences we explicitly excluded contexts where the interaction with AI is the end in itself, such as sex robots and robotic pets, which are increasingly important in the entertainment and healthcare industries. Such applications of AI's communication capability give rise to an AI companionship experience (RQF3). On the one hand, AI companionship experiences are positive because they can provide both cognitive and socioemotional benefits (Broadbent 2017); on the 
other hand, they can deceive vulnerable consumers such as the elderly and toddlers into believing the AI has feelings and may be used as substitutes for real human connections (Van Oost and Reed 2010). While the goal of the creation of robot companions is to simulate an interaction with a real living being, future research could explore at what point the potential for deception and substitution becomes damaging (RQF4).

Finally, emerging AI capabilities may create new consumer AI experiences. In the healthcare sector, nanorobots are being developed to bring AI solutions directly inside the body, and smartphones, fitness trackers, and smart watches provide essential extensions of cognitive and perceptual capabilities. These products give rise to what researchers have called an AI cyborg experience (Giesler and Venkatesh 2005). A cyborg is "a cybernetic organism, a fusion of the organic and the technical forged in particular, historical, cultural practices" (Haraway 1985, p. 51). Thus, cyborg experiences emphasize hybridity, self-enhancement, and often radical self-modification, requiring future research to re-examine longstanding epistemic boundaries between human and machine (Belk 2019). On the one hand, cyborg experiences destabilize human autonomy and control and might fundamentally undermine consumer freedom (Wertenbroch et al. 2020); on the other hand, they collapse dualistic categories like man and machine and might promote consumer empowerment and the circumvention of structural inequalities (RQF5). Lastly, cyborg experiences also raise mind-bending but nonetheless intriguing questions about the kinds of consumption experiences that an AI itself might have (Hoffman and Novak 2018). Consider, in this context, that many firms selling on Amazon today no longer market their offerings directly to consumers but to Amazon-controlled algorithms that act on behalf of these consumers. Future research could explore what marketing strategies are most effective when $\mathrm{AI}$ is marketing to $\mathrm{AI}$ (RQF6). 


\section{Conclusions}

AI-enabled products promise to make consumers happier, healthier, and more efficient. Consumer-facing AI products and services such as college application software, chatbots, and knowledge aggregators have been heralded as forces for good that can make important contributions to problems such as poverty, lack of education, chronic illness, and racial discrimination. For instance, a World Economic Forum discussion on the future of AI argued that "no one will be left behind" (https://bit.ly/3fHRqBi). A key problem with these optimistic celebrations that view AI's alleged accuracy and efficiency as automatic promoters of democracy and human inclusion is their tendency to efface intersectional complexities.

Instead of considering algorithms as neutral tools, AI designers should recognize that their interventions are "inherently political" and interrogate themselves on "the relationship between their design choices, their professional role, and their vision of the good" (Green and Viljoen 2020, 26). We hope that our formulation serves as an antidote to the temptation of “technological solutionism” (Morozov 2013) and a useful guide to contrast cases where targeted consumer segments are subjected to biased outcomes as a result of uncritical firm reliance on AI. We therefore end by noting a key role for the American Marketing Association in shaping the way marketers think about using AI ethically. Although some organizations are beginning to create ethical guidelines around AI, such as the Organization for Economic Co-operation and Development's "Principles for AI” (https://bit.ly/3eykxqH) and the European Commission's "Ethics Guidelines for Trustworthy AI" (https://bit.ly/37Zqmeh), they are not specifically for marketers. The code of conduct of the American Marketing Association currently includes no mention of AI. We recommend the formation of a taskforce of practitioners and academics from 
different disciplines to evaluate how professional guidelines could acknowledge the new ethical challenges raised for marketers by the growth of AI. 


\section{References}

Acquisti, Alessandro, Leslie J. John, and George Loewenstein (2012), "The Impact of Relative Standards on the Propensity to Disclose," Journal of Marketing Research, 49 (2), 160-74.

Adam, Alison (1998), Artificial Knowing: Gender and the Thinking Machine. New York: Routledge.

Agrawal, Ajay, Joshua S. Gans, and Avi Goldfarb (2018), Prediction Machines: The Simple Economics of Artificial Intelligence. Boston: Harvard Business Review Press.

André, Quentin, Ziv Carmon, Klaus Wertenbroch, Alia Crum, Douglas Frank, William Goldstein, Joel Huber, Leaf van Boven, Bernd Weber, and Haiyang Yang (2018), "Consumer Choice and Autonomy in the Age of Artificial Intelligence and Big Data," Customer Needs and Solutions, 5 (1-2), 28-37.

Bandura, Albert (1977), "Self-Efficacy: Toward a Unifying Theory of Behavioral Change," Psychological Review, 84 (2), 191.

Berg, Tobias, Valentin Burg, Ana Gombović, and Manju Puri (2020), “On the Rise of FinTechs: Credit Scoring Using Digital Footprints,” Review of Financial Studies, 33 (7), 2845-2897.

Belk, Russell W. (2019), "Machines and Artificial Intelligence," Journal of Marketing Behavior, 4 (1), 11-30.

Belk, Russell W., Mariam Humayun, and Ahir Gopaldas (2020), “Artificial Life,” Journal of Macromarketing, 20 (10), 1-16.

Bernthal, Matthew J., David Crockett, and Randall L. Rose (2005), "Credit Cards as Lifestyle Facilitators," Journal of Consumer Research, 32 (1), 130-45.

Bettany, Shona M., and Ben Kerrane (2016), “The Socio-materiality of Parental Style: Negotiating the Multiple Affordances of Parenting and Child Welfare within the New Child Surveillance Technology Market," European Journal of Marketing, 50 (11), 2041-66.

Beverland, Michael B., and Francis J. Farrelly (2010), “The Quest for Authenticity in Consumption: Consumers' Purposive Choice of Authentic Cues to Shape Experienced Outcomes," Journal of Consumer Research, 36 (5), 838-56.

Bhattacharjee, Amit, Jonah Berger, and Geeta Menon (2014), "When Identity Marketing Backfires: Consumer Agency in Identity Expression," Journal of Consumer Research, 41 (2), 294-309.

Bone, Sterling A., Glenn L. Christensen, and Jerome D. Williams (2014), "Rejected, Shackled, and Alone: The Impact of Systemic Restricted Choice on Minority Consumers' Construction of Self," Journal of Consumer Research, 41 (2), 451-74.

Bonnefon, Jean-François, Azim Shariff, and Iyad Rahwan (2016), “The Social Dilemma of Autonomous Vehicles," Science, 352 (6293), 1573-76.

Borgerson, Janet (2005), "Materiality, Agency, and the Constitution of Consuming Subjects: Insights for Consumer Research," in North American Advances in Consumer Research, Vol. 32, Geeta Menon, and Akshay R. Rao, eds. Duluth, MN: Association for Consumer Research, 439-43. 
Botti, Simona and Ann L. McGill (2011), "The Locus of Choice: Personal Causality and Satisfaction with Hedonic and Utilitarian Decisions," Journal of Consumer Research, 37 (6), 1065-78.

Botti, Simona, and Sheena S. Iyengar (2006), "The Dark Side of Choice: When Choice Impairs Social Welfare,” Journal of Public Policy \& Marketing, 25 (1), 24-38.

Brakus, J. Joško, Bernd H. Schmitt, and Lia Zarantonello (2009), "Brand Experience: What Is It? How Is It Measured? Does It Affect Loyalty?,” Journal of Marketing, 73 (3), 52-68.

Branscombe, Nyla R., and Daniel L. Wann (1994), "Collective Self-Esteem Consequences of Outgroup Derogation when a Valued Social Identity is on Trial," European Journal of Social Psychology, 24 (6), 641-57.

Brehm, Jack W. (1966), A Theory of Psychological Reactance. New York: Academic Press.

Broadbent, Elizabeth (2017), "Interactions with Robots: The Truths We Reveal About Ourselves," Annual Review of Psychology, 68, 627-52.

Brunk, Katja H., Markus Giesler, and Benjamin J. Hartmann (2017), "Creating a Consumable Past: How Memory Making Shapes Marketization," Journal of Consumer Research, 44 (6), $1325-42$.

Campbell, Margaret C., Gina S. Mohr, and Peeter W. Verlegh (2013), "Can Disclosures Lead Consumers to Resist Covert Persuasion? The Important Roles of Disclosure Timing and Type of Response," Journal of Consumer Psychology, 23 (4), 483-95.

Carmon, Ziv, Rom Y. Schrift, Klaus Wertenbroch, and Haiyang Yang (2020), "Designing AI Systems that Customers Won't Hate," MIT Sloan Management Review, 61(2), 1-6.

Castelo, Noah, Maarten W. Bos, and Donald R. Lehmann (2019), "Task-dependent Algorithm Aversion," Journal of Marketing Research, 56 (5), 809-25.

Chan, Cindy, Jonah Berger, and Leaf Van Boven (2012), "Identifiable But Not Identical: Combining Social Identity and Uniqueness Motives in Choice," Journal of Consumer Research, 39 (3), 561-73.

Chernev, Alexander, Ulf Böckenholt, and Joseph Goodman (2015), "Choice Overload: A Conceptual Review and Meta-analysis," Journal of Consumer Psychology, 25 (2), 333-58.

Crenshaw, Kimberle (1989), "Demarginalizing the Intersection of Race and Sex: A Black Feminist Critique of Antidiscrimination Doctrine, Feminist Theory and Antiracist Politics," University of Chicago Legal Forum, Vol. 1989, Article 8.

Crocker, Jennifer and Brenda Major (1989), "Social Stigma and Self-Esteem: The SelfProtective Properties of Stigma," Psychological Review, 96, 608.

Cutright, Keisha M. and Adriana Samper (2014), "Doing It the Hard Way: How Low Control Drives Preferences for High-Effort Products and Services," Journal of Consumer Research, 41 (3), 730-45.

Dahl, Darren W. and C. Page Moreau (2007), "Thinking Inside the Box: Why Consumers Enjoy Constrained Creative Experience," Journal of Marketing Research, 44 (3), 357-69.

DeCharms, Richard (1968), Personal Causation. New York: Academic Press. 
Dietvorst, Berkeley J., Joseph P. Simmons, and Cade Massey (2016), "Overcoming Algorithm Aversion: People will use Imperfect Algorithms if They can (Even Slightly) Modify Them," Management Science, 64 (3), 1155-70.

Dobbin, Frank, and Alexandra Kalev (2016), "Why Diversity Programs Fail," Harvard Business Review, 94 (7), 52-60.

Epp, Amber M., Hope Jensen Schau, and Linda L. Price (2014), "The Role of Brands and Mediating Technologies in Assembling Long-Distance Family Practices," Journal of Marketing, 78 (3), 81-101.

Etkin, Jordan (2016), "The Hidden Cost of Personal Quantification," Journal of Consumer Research, 42(6), 967-84.

Eubanks, Virginia (2018), Automating Inequality: How High-Tech Tools Profile, Police and Punish the Poor. New York: St. Martin's Press.

Farooq, Umer, and Jonathan Grudin (2016), "Human-Computer Integration," IX Interactions, 6 (November), available at: http://interactions.acm.org/archive/view/november-december2016/human-computer-integration.

Fishbach, Ayelet and Jinhee Choi (2012), "When Thinking about Goals Undermines Goal Pursuit," Organizational Behavior and Human Decision Processes, 118 (2), 99-107.

Fitzsimons, Gavan, and Donald R. Lehmann (2004), "Reactance to Recommendations: When Unsolicited Advice Yields Contrary Responses," Marketing Science, 23 (1), 82-94.

Flaxman, Seth, Sharad Goel, and Justin M. Rao (2016), "Filter Bubbles, Echo Chambers, and Online News Consumption," Public Opinion Quarterly, 80 (S1), 298-320.

Fredrickson, Barbara L. and Tomi-Ann Roberts (1997), "Objectification Theory: Toward Understanding Women's Lived Experiences and Mental Health Risks," Psychology of Women Quarterly, 21 (2), 173-206.

Friestad, Marian, and Peter Wright (1994), "The Persuasion Knowledge Model: How People Cope with Persuasion Attempts," Journal of Consumer Research, 21 (1), 1-31.

Fuchs, Christoph, Emanuela Prandelli, and Martin Schreier (2010), "The Psychological Effects of Empowerment Strategies on Consumers' Product Demand," Journal of Marketing, 74 (1), 65-79.

Fukuyama, Francis (2002), Our Posthuman Future. New York: Farrar, Straus and Giroux.

Gai, Phyliss Jia and Anne-Kathrin Klesse (2019), "Making Recommendations More Effective Through Framings: Impacts of User-Versus Item-Based Framings on Recommendation ClickThroughs," Journal of Marketing, 83 (6), 61-75.

Giesler, Markus and Eileen Fischer (2018), "IoT Stories: The Good, the Bad and the Freaky," Marketing Intelligence Review, 10 (2), 24-8.

Giesler, Markus and Ashlee Humphreys (2007), "Tensions between Access and Ownership in the Media Marketplace," in NA-Advances in Consumer Research, Vol. 34, Gavan Fitzsimons, and Vicki Morwitz, eds. Duluth, MN: Association for Consumer Research, 696-700. 
Giesler, Markus, and Alladi Venkatesh (2005), "Reframing the Embodied Consumer as Cyborg: A Posthumanist Epistemology of Consumption," in NA-Advances in Consumer Research, Vol. 32, Geeta Menon, and Akshay R. Rao, eds. Duluth, MN: Association for Consumer Research, 661-69.

Gill, Tripat (2020), "Blame It on the Self-Driving Car: How Autonomous Vehicles Can Alter Consumer Morality," Journal of Consumer Research, forthcoming.

Grafanaki, Sofia (2017), "Autonomy Challenges in the Age of Big Data," Fordham Intellectual Property, Media \& Entertainment Law Journal, 27, 803.

Granulo, Armin, Christoph Fuchs, and Stefano Puntoni (2020), "Preference for Human (vs. Robotic) Labor is Stronger in Symbolic Consumption Contexts," Journal of Consumer Psychology, forthcoming.

Green, Ben, and Salomé Viljoen (2020), "Algorithm Realism: Expanding the Boundaries of Algorithmic Thought," in Proceedings of the 2020 Conference on Fairness, Accountability, and Transparency, January, 19-31.

Grudin, Jonathan (2017), From Tool to Partner: The Evolution of Human-Computer Interaction. San Rafael, CA: Morgan and Claypool Publishers.

Habermas, Jurgen (2003), The Future of Human Nature. London: Polity.

Hadi, Rhonda, Lauren Bock, Sandra Robinson, and Jessie Du (2020) "When Alexa Lets Us Down: Conversational Failures with Female Artificial Intelligence Lead to Greater Expressed Frustration," working paper.

Hart, Christopher W., James L. Heskett, and W. Earl Sasser Jr. (1990), "The Profitable Art of Service Recovery," Harvard Business Review, 68 (4), 148-56.

Haslam, Nick (2006), "Dehumanization: An Integrative Review," Personality and Social Psychology Review, 10 (3), 252-64.

Harari, Yuval N. (2017), Homo Deus: A Brief History of Tomorrow. London: Penguin Publishing.

Haraway, Donna (1985), "A Manifesto for Cyborgs: Science, Technology and Socialist Feminism in the 1980s," Socialist Review, (80), 65-107.

Hayek, Friedrich (1945), "The Use of Knowledge in Society," The American Economic Review, 35, 519-30.

Hayles, N. Katherine (1999), How We Became Posthuman: Virtual Bodies in Cybernetics, Literature, and Informatics. Chicago: University of Chicago Press.

Hill, Ronald and Eesha Sharma (2020), "Consumer Vulnerability," Journal of Consumer Psychology, https://doi.org/10.1002/jcpy.1161.

Hoffman, Donna L. and Thomas P. Novak (2018), "Consumer and Object Experience in the Internet of Things: An Assemblage Theory Approach," Journal of Consumer Research, 44 (6), 1178-04.

Hosanagar, Kartik (2019), A Human's Guide to Machine Intelligence: How Algorithms are Shaping Our Lives and How We Can Stay in Control. New York: Viking. 
Humphreys, Ashlee (2010), "Semiotic Structure and the Legitimation of Consumption Practices: The Case of Casino Gambling," Journal of Consumer Research, 37 (3), 490-510.

Iyengar, Sheena and Mark Lepper (2000), "When Choice is Demotivating: Can One Desire Too Much of a Good Thing?” Journal of Personality and Social Psychology, 79 (6), 995-1006.

Ivarsflaten, Elisabeth, Scott Blinder, and Robert Ford (2010), “The Anti-Racism Norm in Western European Immigration Politics: Why we Need to Consider it and How to Measure it," Journal of Elections, Public Opinion and Parties, 20 (4), 421-45.

JWT Intelligence Wunderman Thompson (2016), "Control Shift,” Available at: https://www.jwtintelligence.com/trend-reports/control-shift/

Kim, Sara, Rocky Peng Chen, and Ke Zhang, (2016), “Anthropomorphized Helpers Undermine Autonomy and Enjoyment in Computer Games," Journal of Consumer Research, 43 (2), 282302.

Kim, Sara, and Ann L. McGill (2011), "Gaming with Mr. Slot or Gaming the Slot Machine? Power, Anthropomorphism, and Risk Perception," Journal of Consumer Research, 38 (1), 94107.

Kumar, V., Barath Rajan, Rajkumar Vennkatesan, and Jim Lecinski (2019), "Understanding the Role of Artificial Intelligence in Personalized Engagement Marketing," California Management Review, 61 (4), 135-55.

Kunda, Ziva (1990). "The Case for Motivated Reasoning, Psychological Bulletin, 108 (3), 48098.

Kuniavsky, Mike (2010), Smart Things: Ubiquitous Computing User Experience Design. Burlington, MA: Morgan Kauffman Elsevier.

Landau, Mark J., Aaron C. Kay, and Jennifer A. Whitson (2015), "Compensatory Control and the Appeal of a Structured World,” Psychological Bulletin, 141 (3), 694-722.

Lee, Leonard, Shane Frederick, and Dan Ariely (2006), “Try It, You'll Like It: The Influence of Expectation, Consumption, and Revelation on Preferences for Beer," Psychological Science, 17 (12), 1054-58.

Lemon, Katherine N. and Peter C. Verhoef (2016), "Understanding Customer Experience Throughout the Customer Journey," Journal of Marketing, 80 (6), 69-96.

Leotti, Lauren A., Sheena S. Iyengar, and Kevin N. Ochsner (2010), "Born to Choose: The Origins and Value of the Need for Control," Trends in Cognitive Sciences, 14 (10), 457-63.

Leung, Eugina, Gabriele Paolacci, and Stefano Puntoni (2018), "Man Versus Machine: Resisting Automation in Identity-based Consumer Behavior," Journal of Marketing Research, 55 (6), 818-31.

Longoni, Chiara, Andrea Bonezzi, and Carey Morewedge (2019), "Resistance to Medical Artificial Intelligence," Journal of Consumer Research, 46 (3), 407-34.

Luo, Xueming, Siliang Tong, Zheng Fang, and Zhe Qu (2019), "Machines Versus Humans: The Impact of AI Chatbot Disclosure on Customer Purchases," Marketing Science, 38 (6), 937-47.

Marketing Science Institute (2018), Research Priorities 2018-2020. Cambridge, Mass.: Marketing Science Institute. 
Marks, Susan (2005). Finding Betty Crocker: The Secret Life of America's First Lady of Food. Simon \& Schuster.

Markus, Hazel Rose and Barry Schwartz (2010), "Does Choice Mean Freedom and WellBeing?" Journal of Consumer Research, 37 (2), 344-55.

Martin, Kelly D. and Patrick E. Murphy (2017), "The Role of Data Privacy in Marketing," Journal of the Academy of Marketing Science, 45, 135-55.

Matz, Sandra C., Michael Kosinski, Gideon Nave, and David J. Stillwell (2017), "Psychological Targeting as an Effective Approach to Digital Mass Persuasion," Proceedings of the National Academy of Sciences, November, 12714-19.

MacCarthy, Mark (2019), “An Examination of the Algorithmic Accountability Act of 2019," https://ssrn.com/abstract=3615731.

Melumad, Shiri and Robert Meyer (2020), "Full Disclosure: How Smartphones Enhance Consumer Self-Disclosure," Journal of Marketing, 84(3), 28-45.

Mende, Martin, Maura L. Scott, Jenny van Doorn, Dhruv Grewal, and Ilana Shanks (2019), "Service Robots Rising: How Humanoid Robots Influence Service Experiences and Elicit Compensatory Consumer Responses," Journal of Marketing Research, 56 (4), 535-56.

Mick, David G. and Susan Fournier (1998), "Paradoxes of Technology: Consumer Cognizance, Emotions, and Coping Strategies," Journal of Consumer Research, 25 (2), 123-43.

Mittal, Chiraag and Vladas Griskevicius (2014), "Sense of Control Under Uncertainty Depends on People's Childhood Environment: A Life History Theory Approach," Journal of Personality and Social Psychology, 107 (4), 621-37.

Moon, Youngme and Clifford Nass (1998), "Are Computers Scapegoats? Attributions of Responsibility in Human-Computer Interaction," International Journal of Human-Computer Studies, 49, 79-94

Mou, Yi and Kun Xu (2017), "The Media Inequality: Comparing the Initial Human-Human and Human-AI Social Interactions," Computers in Human Behavior, 72, 432-40.

Morozov, Evgeny (2013), To Save Everything, Click Here: The Folly of Technological Solutionism. New York: Public Affairs.

Nass, Clifford and Youngme Moon (2000), "Machines and Mindlessness: Social Responses to Computers," Journal of Social Issues, 56 (1), 81-103.

Noble, Safiya Umoja (2018), Algorithms of Oppression: How Search Engines Reinforce Racism. New York: NYU Press.

Norton, Michael I., Daniel Mochon, and Dan Ariely (2012), "The IKEA Effect: When Labor Leads to Love," Journal of Consumer Psychology, 22 (3), 453-60.

O'Neil, Cathy (2016), Weapons of Math Destruction: How Big Data Increases Inequality and Threatens Democracy. New York: Broadway Books.

Oyserman, Daphna (2009), "Identity-based Motivation and Consumer Behavior," Journal of Consumer Psychology, 19 (3), 250-60.

Owens, Eric W., Richard J. Behun, Jill C. Manning, and Rory C. Reid (2012), “The Impact of 
Internet Pornography on Adolescents: A Review of the Research," Sexual Addiction \& Compulsivity, 19 (1-2), 99-122.

Polanyi, Michael (1948), "Planning and Spontaneous Order," The Manchester School, 16, September, 237-68.

Porter, Theodore (1996), Trust in Numbers. Princeton: Princeton University Press.

Reed II, Americus, Mark R. Forehand, Stefano Puntoni, and Luk Warlop (2012), "Identity-based Consumer Behavior,” International Journal of Research in Marketing, 29 (4), 310-21.

Sassen, Saskia (2014), Expulsions. Cambridge: Harvard University Press.

Schmitt, Bernd (2019), "From Atoms to Bits and Back: A Research Curation on Digital Technology and Agenda for Future Research," Journal of Consumer Research, 46 (4), 82532.

Schumpeter, Joseph A. (1942), Capitalism, Socialism and Democracy. New York: Harper.

Seaver, Nick (2019), "Knowing Algoriths," in digitalSTS: A Field Guide for Science and Technology Studies, Janet Vertesi, and David Ribes, eds. Princeton: Princeton University Press, 412-22.

Suchman, Lucy, Celia Roberts, and Myra J. Hird (2011), "Subject Objects," Feminist Theory, 12 (2), 119-45.

Summers, Christopher A., Robert W. Smith, and Rebecca Walker Reczek (2016), "An Audience of One: Behaviorally Targeted Ads as Implied Social Labels," Journal of Consumer Research, 43 (1), 156-78.

Sunstein, Cass R. (2015), Choosing Not to Choose: Understanding the Value of Choice. Oxford: Oxford University Press.

Thaler, Richard H., and Shlomo Benartzi (2004) "Save More Tomorrow ${ }^{\mathrm{TM}}$ : Using Behavioral Economics to Increase Employee Saving," Journal of Political Economy, 112 (S1), S164-87.

Tuk, Mirjam A., Peeter W. Verlegh, Ale Smidts, and Daniel H. Wigboldus (2009), "Sales and Sincerity: The Role of Relational Framing in Word-of-Mouth Marketing," Journal of Consumer Psychology, 19 (1), 38-47.

Turkle, Sherry (2008), "Always-on/Always-on-you: The Tethered Self," in Handbook of Mobile Communication Studies, James E. Katz, ed. Cambridge: MIT Press.

Turner, John C. and Katherine J. Reynolds (2011), "Self-categorization Theory," in Handbook of Theories in Social Psychology, Vol. 2, Paul AM Van Lange, Arie W. Kruglanski, and E. Tory Higgins, eds. 399-417.

van Doorn, Jenny, Martin Mende, Stephanie M. Noble, John Hulland, Amy L. Ostrom, Dhruv Grewal, and J. Andrew Petersen (2017), "Domo Arigato Mr. Roboto: Emergence of Automated Social Presence in Organizational Frontlines and Customers' Service Experiences," Journal of Service Research, 20 (1), 43-58.

van Oost, Ellen and Darren Reed (2010), “Towards a Sociological Understanding of Robots as Companions," in Human-Robot Personal Relationships: Lecture Notes of the Institute for Computer Sciences, Social Informatics and Telecommunications Engineering, Ellen Van Oost, and Darren Reed, eds. Berlin: Springer, 59. 
van Osselaer, Stijn M.J., Chistoph Fuchs, Martin Schreier, and Stefano Puntoni (2020), “The Power of Personal," Journal of Retailing, 96(1), 88-100.

Walker, Kristen L. (2016), "Surrendering Information through the Looking Glass: Transparency, Trust, and Protection,” Journal of Public Policy \& Marketing, 35 (1), 144-58.

Waytz, Adam, Joy Heafner, and Nicholas Epley (2014), "The Mind in the Machine: Anthropomorphism Increases Trust in an Autonomous Vehicle," Journal of Experimental Social Psychology, 52, 113-17.

Wertenbroch, Klaus, Rom Y. Schrift, Joseph W. Alba, Alixandra Barasch, Amit Bhattacharjee, Markus Giesler, Joshua Knobe, Donald R. Lehmann, Sandra Matz, Gideon Nave, Jeffrey R. Parker, Stefano Puntoni, Yanmei Zheng, and Yonat Zwebner (2020), "Autonomy in Consumer Choice," Marketing Letters, https://doi.org/10.1007/s11002-020-09521-z.

West, Mark, Rebecca Kraut, and Han Ei Chew (2019), I'd Blush if I Could: Closing Gender Divides in Digital Skills Through Education. EQUALS.

Wierenga, Berend, and Peter AM Oude Ophuis (1997), "Marketing Decision Support Systems: Adoption, Use, and Satisfaction," International Journal of Research in Marketing, 14 (3), 275-90.

Wright, Peter (2002), "Marketplace Metacognition and Social Intelligence," Journal of Consumer Research, 28 (March), 677-82.

Zuboff, Shoshana (2019), The Age of Surveillance Capitalism: The Fight for a Human Future at the New Frontier of Power. NY: Profile Books.

Zou, James and Londa Schiebinger (2019), “AI Can Be Sexist and Racist - It's Time to Make It Fair," Nature, 559, 324-26. 


\section{FIGURE 1: THE CONSUMER AI EXPERIENCE}

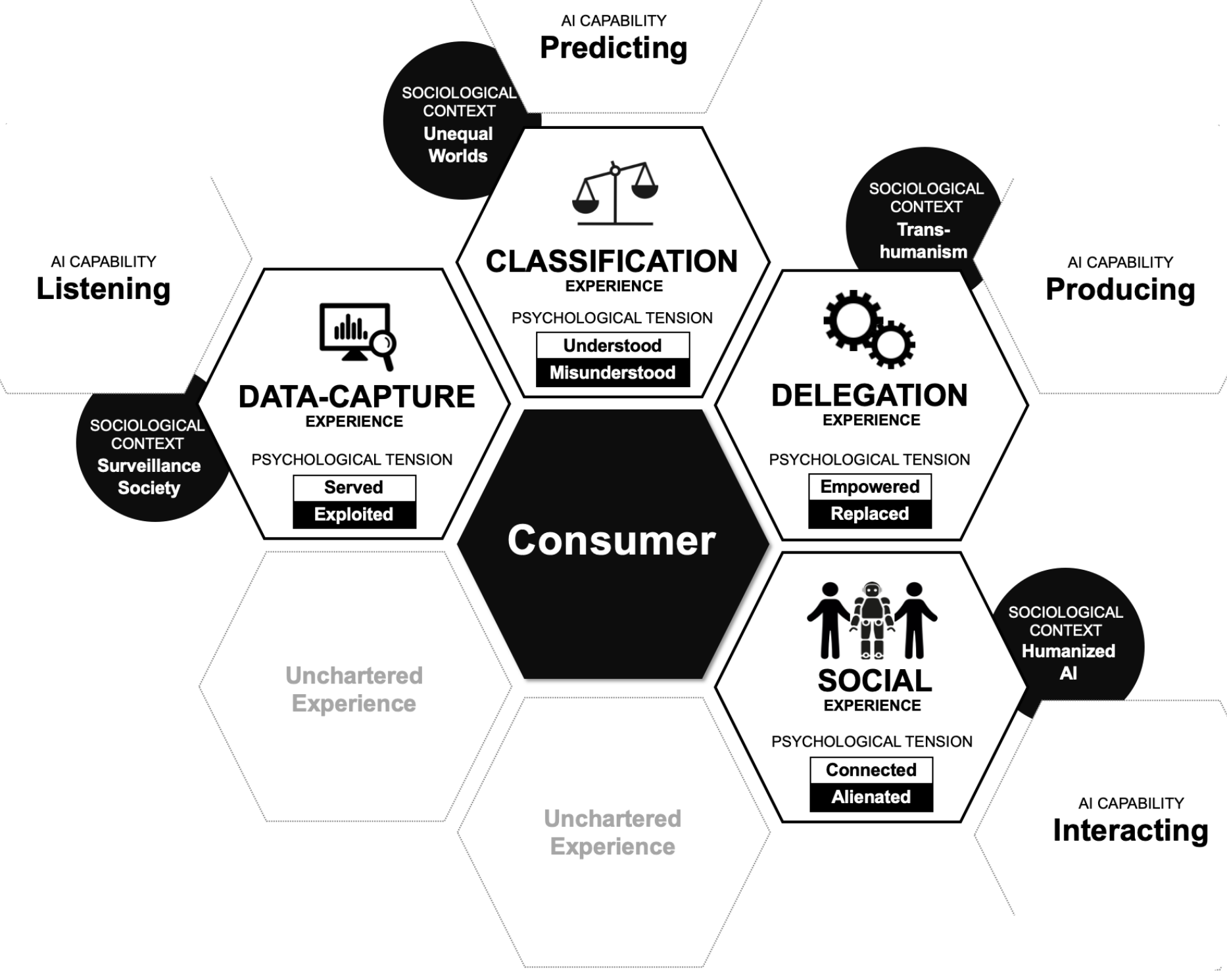


TABLE 1:

CONSUMERS AND AI EXPERIENCE: EMERGING RESEARCH QUESTIONS (RQ)

\section{A: The AI Data-Capture Experience}

RQA1: How does socio-economic status influence the likelihood of feeling exploited?

RQA2: How do cultural norms influence the likelihood of feeling exploited?

RQA3: How does intersectionality normalize or problematize exploitation?

RQA4: How does the diffusion of AI affect feelings of exploitation over time?

RQA5: How does motivated reasoning shape consumer affective reactions in data-capture experiences?

RQA6: How does the frequency of data-capture affect perceived exploitation over time?

RQA7: How are feelings of exploitation influenced by the nature of the data collected (e.g., environmental, behavioral, physiological)?

RQA8: How does the physical context of data collection affect the likelihood of feeling exploited?

RQA9: Does the experience of data-capture depend on the device the consumer is using?

RQA10: When and how will consumer sabotage data collection by AI in response to feelings of exploitation?

\section{B: The AI Classification Experience}

RQB1: How do individual differences in awareness of discrimination affect whether a consumer feels misunderstood by the AI?

RQB2: How do the social classifications inscribed into AI solutions shape consumer behavior and choices?

RQB3: How do consumers infer which variables the AI is using to make personalized predictions?

RQB4: Which types of inferred classifications are more likely to make consumers feel misunderstood?

RQB5: How do uniqueness versus belonging motives affect the likelihood of feeling misunderstood? RQB6: How does the nature of the task influence the likelihood of feeling misunderstood?

\section{C: The AI Delegation Experience}

RQC1: How do feelings of being replaced depend on the perceived "humanness" of an activity?

RQC2: How does feeling replaced by AI affect the perceived acceptability of various behaviors designed to protect or promote the self?

RQC3: As the range of tasks that AI can perform increases over time, how do normative task boundaries around humans versus algorithms shift?

RQC4: What specific consumption contexts make delegation to AI more psychologically aversive?

RQC5: Do consumers compensate for feelings of being replaced by AI in non-consumption domains?

RQC6: How do instrumental versus symbolic consumption motives determine perceptions of being replaced?

RQC7: Is the likelihood of feeling replaced affected by whether consumers focus on consumption outcomes versus process?

RQC8: When and how do consumers respond to threats of replacement by AI by fencing off the AI? 


\section{D: The AI Social Experience}

RQD1: How anti-bias beliefs affect alienation in social experiences?

RQD2: How do cultural differences influence consumer perceptions of social experiences?

RQD3: What are the consequences of AI-enabled social experiences for important societal processes such as children's socialization and gender relations?

RQD4: When are customers more likely to objectify the AI in responses to alienation?

RQD5: How does the timing of disclosure influence the likelihood of consumer alienation?

RQD6: What is the influence of situational characteristics on alienation?

RQD7: What is the role of brand equity in reducing or facilitating alienation?

\section{E: Interrelationship Between AI Experiences}

RQE1: How do the ways in which consumers experience data-capture influence perceived resource accessibility in a classification experience?

RQE2: Does aggressive data-capture strengthen or weaken social inclusion?

RQE3: Does involving consumers in the validation of assumptions about their preferences shift a classification experience to feel more like a delegation experience?

RQE4: Do changes in feelings of control lead to parallel shifts in data-capture and delegation experiences?

RQE5: Do changes in consumer self-identity concerns lead to parallel shifts in classification and social experiences?

RQE6: Are data-capture experiences less aversive when demands for data increase together with feelings of empowerment from delegation experiences?

\section{F: Unchartered AI Experiences}

RQF1: How does the learner-AI interaction shape learning experiences and impact student satisfaction, motivation, and learning?

RQF2: How does the valence of learning experiences depend on identity relevance and internal attribution of learning outcomes?

RQF3: What motivates consumers to have AI-enabled companionship experiences?

RQF4: What factors determine whether consumers perceive companionship experiences as deceptive or alienating?

RQF5: How do AI solutions that permeate epistemic boundaries between human and machine impact consumer autonomy?

RQF6: How does AI perceive and experience the world and marketplace, and how can firms design these experiences effectively? 